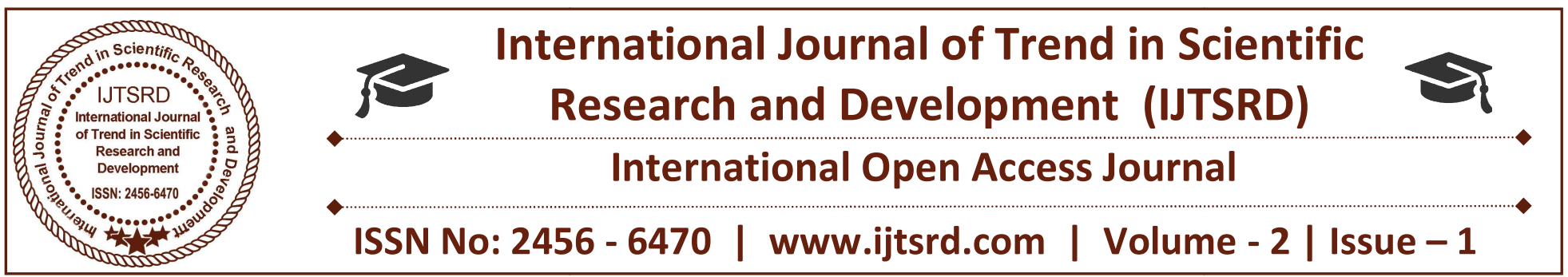

\title{
A Novel Technique of Power Extraction from A Conventional Fluorescent Lamp
}

\author{
Parantap Nandi \\ Calcutta University, Kolkata, West Bengal
}

\begin{abstract}
Fluorescent lamps are commonly used in our homes as a source of light. The conventional lamps use a choke and a starter arrangement for starting discharge in the tube. Under normal working conditions an appreciable potential drop occurs across the choke. The circuit being inductive the power factor is also low. Now is there any way of utilizing this voltage drop? Experiments were carried out with a view to using this potential drop to provide energy at low wattage without hampering the normal operation of the tube light. Interesting results were obtained. The power factor was also found to improve. In this paper a method of utilizing the voltage drop across the choke of a fluorescent lamp as a source of energy has been elaborated.
\end{abstract}

Keywords: Choke; Power factor; Energy; Tube Light

\section{Introduction}

In the present day civilization, the energy crisis is ever increasing in leaps and bounds. The need of using energy efficient devices is undeniable. But one hardly ponders over the process of saving/utilizing energy from the existing equipments themselves. A very good instance is a fluorescent lamp commonly referred to as 'tube light'. In addition to the lamp itself and its holder, it requires a choke or ballast and a make-break switch commonly referred to as starter. Before proceeding further a brief description of the starting and working of a tube light is essential. When the switch is made ON the full voltage is applied through the ballast and starter which establishes glow discharge in the starter. As a result of the discharge in the starter a current is established this causes a potential drop across the choke which tends to extinguish the discharge. As the current gets interrupted, the choke develops an inductive kick given by the relation $\mathrm{e}=\mathrm{Ldi} / \mathrm{dt}$. This high voltage comes across the tube electrodes and strikes the penning mixture. Gas discharge inside the tube is initiated inside the tube and current starts flowing. The starter becomes inactive.

These days' fluorescent lamp installations come with electronic ballasts which eliminate the need for a starter and are what we call 'instant start'. These ballasts are undoubtedly energy saving and have a high power factor $(\geq .9)$.

But the existing fixtures still use magnetic ballasts and starters (the operating principle given above). The power factor of these ballasts is quite low compared with electronic ballasts. The tubes fitted with magnetic ballasts and starters show two tendencies:-

I. With aging, the lumen output of the lamp decreases and the lamp gets dimmer. Finally the lamp refuses to start and only flickers as the production of a steady discharge becomes impossible. The only choice is to replace the old tube.

II. When the supply voltage is low, the magnetic ballast is unable to produce steady discharge in the lamp. It continues to flicker. In this case mostly the magnetic ballast is replaced by an electronic one.

The above solutions rely on the 'replacement of an existing device in good working condition'. So basically we abandon existing technology and resort to new ones. 
Now is there any way by which we need not replace an existing device but still get maximum output? With a view to finding the answer, experiments were conducted on a conventional fluorescent lamp using magnetic ballast and interesting results were obtained.

\section{Materials and apparatus required:}

1. Fluorescent lamp (tube light) $36 / 40 \mathrm{~W}$.

2. Copper choke.

3. Starter

4. Transformer $230 / 9 \mathrm{~V}, 450 \mathrm{~mA}$.

5. Sensitive digital multimeter

6. Incandescent lamps (standard wattages)

7. $4 \mathrm{~W}$ LED lamp

8. 14W CFL lamp

9. Power factor meter

$10.5 \mathrm{~V}$ battery charger

11. D.C motor (fan)

12. Capacitor $2.5 \mu \mathrm{F}$ (used with ceiling fans) 13. 1 N5408 diodes
Experimental: A conventional tube light working using a magnetic ballast and starter was used in this experiment. During the next sections the magnetic ballast has been referred to as choke. When a tube light is in the normal working condition, the choke acts as a current limiting agent and the starter remains inactive. It is evident from the fact that on opening the starter the normal working of the light is unaffected. So there are two devices from which power might be extracted i.e. the open starter terminals and the choke terminals. Keeping these in mind the several experiments were conducted which have been elaborated in the succeeding parts.

\section{Experiment no. 1}

A load was connected across the choke of a tube light. The remaining circuit was left as it is. The load was varied in steps from zero to $100 \mathrm{~W}$. The following table was tabulated:-

Table no. 1

\begin{tabular}{|c|c|c|}
\hline Load in Watts & $\begin{array}{c}\text { Voltage across choke-load } \\
\text { combination in Volts }\end{array}$ & $\begin{array}{c}\text { Voltage across open starter terminal } \\
\text { in Volts }\end{array}$ \\
\hline 0 & 170 & 125 \\
\hline 4 & 155 & 123 \\
\hline 5.3 & 150 & 115 \\
\hline 14 & 145 & 118 \\
\hline 15 & 155 & 120 \\
\hline 40 & 140 & 110 \\
\hline 60 & 137.5 & 110 \\
\hline 100 & 130 & 105 \\
\hline
\end{tabular}

A curve plotted gives a better understanding of the phenomena:-

Graph no.1

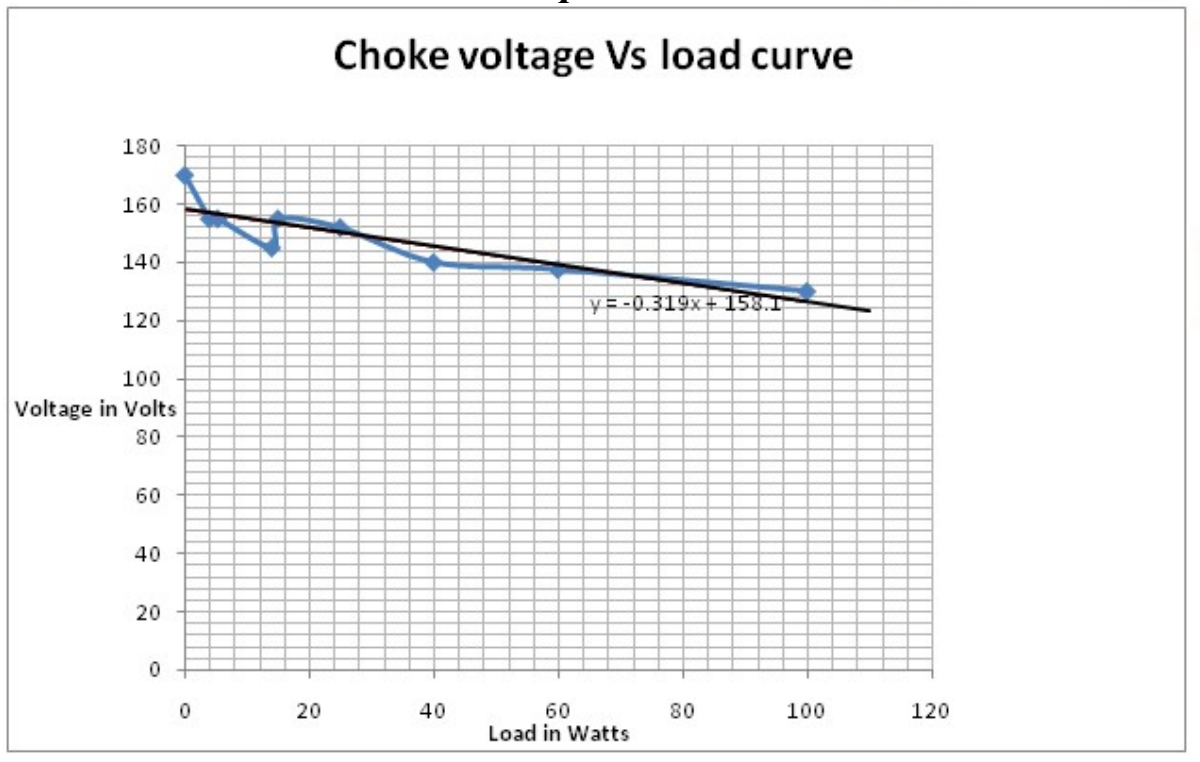


The trend line (shown in black) explains the operating characteristics quite well. A load beyond 100W was not used because it would increase the filament voltage beyond the tolerable limit and might damage the tube.

A linear trend line indicates the presence of a 'maximum load' at which voltage across the choke should become zero. But this would mean that the parallel combination of load and choke acts as short circuit. If such were the case two things would occur:

I. The current limiting action of the choke would be lost and the fluorescent lamp would be subjected to full supply voltage which would immediately destroy it.

II. The tube light may not strike at all.

Careful experiments showed that a maximum of $150 \mathrm{~W}$ could be applied across the choke and this too depends on the condition of the tube. For an old tube light a maximum of $125 \mathrm{~W}$ may be applied.

Graph no.2

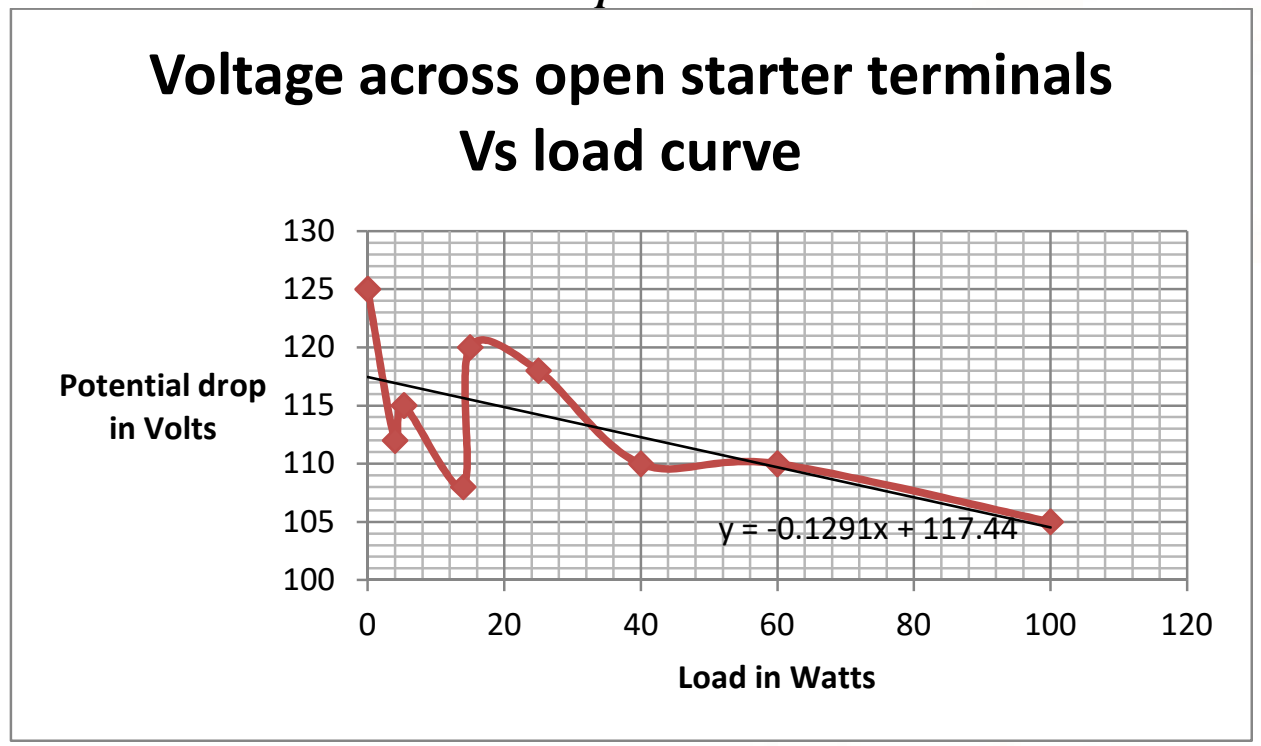

As the load is increased the tube light glows brighter which is visible to the naked eye. This was also measured by appropriate arrangements. The following curve illustrates the same.

Graph no.3

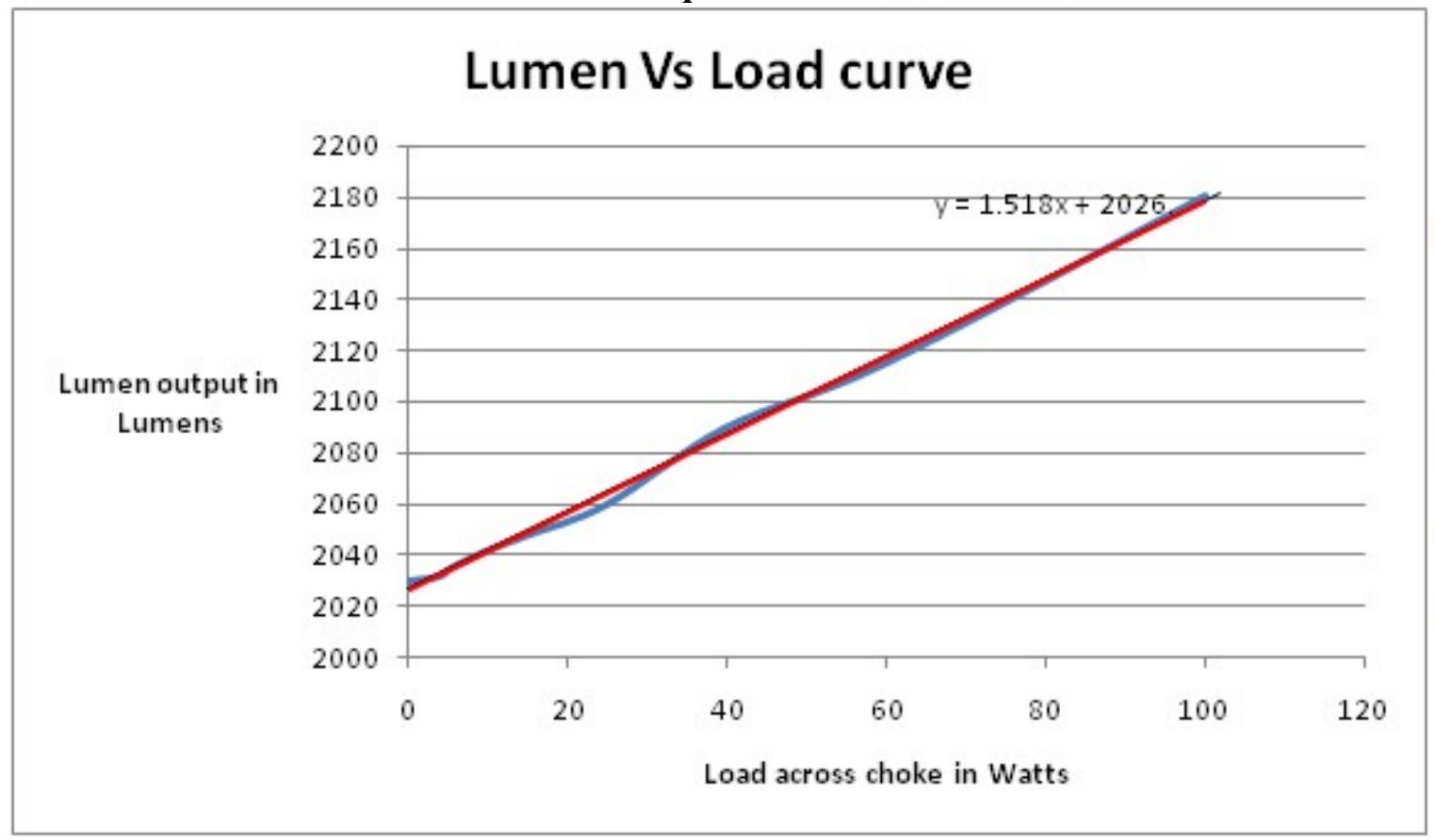

It is evident that the light output increases linearly with increase in load across the choke. 
$>$ Experiment no.2

The voltage across the choke was rectified using a bridge rectifier (making use of 4 diodes). A plot of D.C terminal voltage Vs load current was plotted.

Graph no. 4

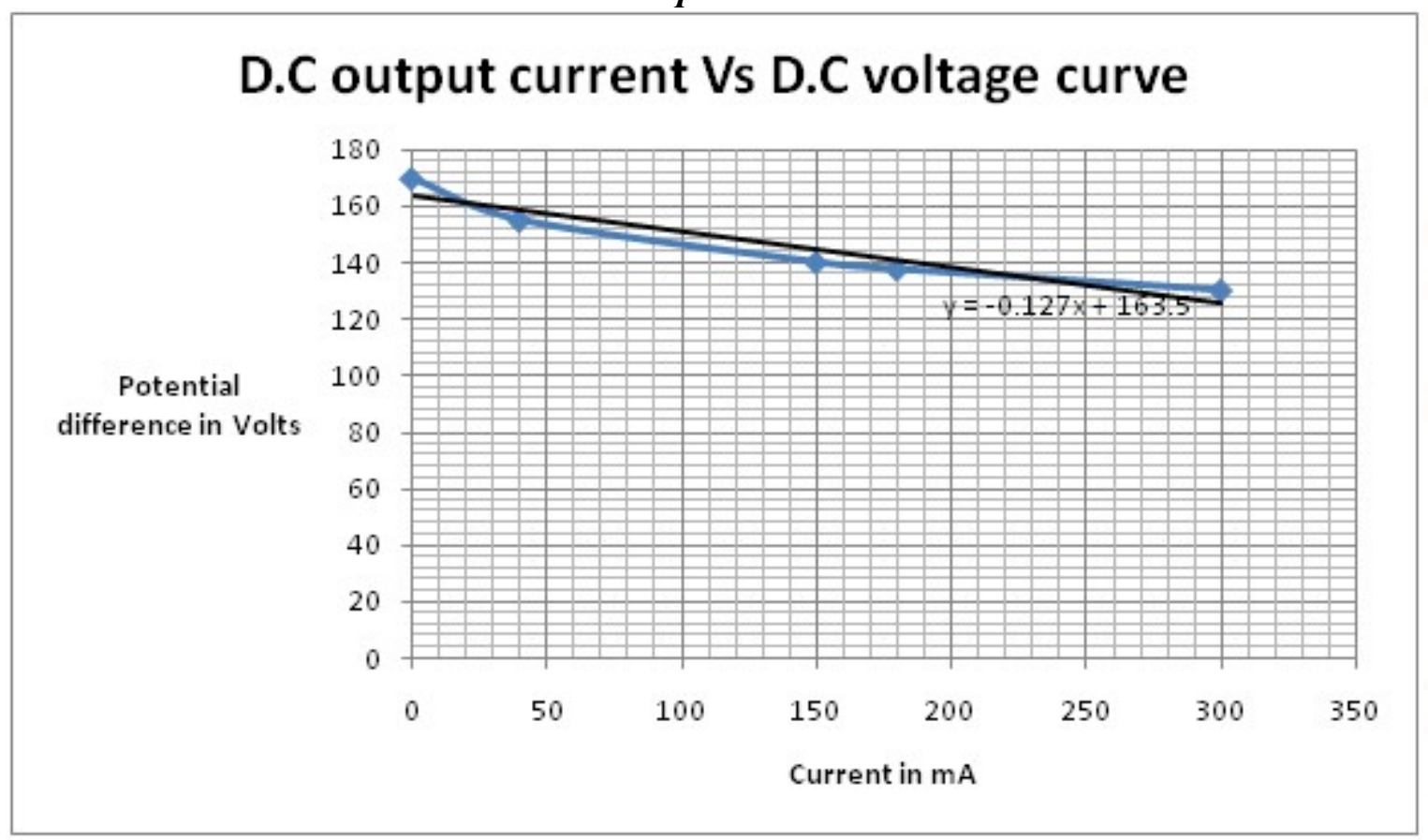

Again it is evident that the terminal voltage decreases linearly with load current. An interesting thing was observed on connecting a D.C motor at the rectifier terminal. The tube light started flickering at the ends and the frequency of the flickers was equal to the frequency of rotation of the shaft.

As the D.C output current increased the tube light grew brighter.

\section{$>$ Experiment no.3}

The H.V side of a $230-9 \mathrm{~V}, 450 \mathrm{~mA}$ transformer was connected in parallel with the choke. The transformer has considerable inductance. When connected in parallel with the choke $\mathrm{L}_{\text {effective }}=\frac{L 1 L 2}{L 1+L 2}$. So the overall inductance decreases. In the steady state the voltage across the transformer primary is $137.5 \mathrm{~V}$ while that across the secondary is $6.4 \mathrm{~V}$. On shorting the L.V side, there is no change in the primary voltage and consequently no change in the filament voltage of the tube light. So the filament voltage is maintained independent of the load on the transformer. This proves that power can be extracted at low voltage, variable current using a transformer in parallel with the choke.

\section{$>$ Experiment no. 4}

The best possible way to extract power is perhaps charging of a battery. The voltage across the choke is capable of charging a $5 \mathrm{~V}$ battery using an auxiliary charger whose input is the choke voltage. This is yet another way of obtaining energy at a low voltage from the choke.

\section{Experiment no.5}

With a view to improving power factor, a capacitor of $2.5 \mu \mathrm{F}$ used in ceiling fans is connected across the choke. But it has a detrimental effect; it does not allow the tube light to strike. This may be explained in the following way:

At the time of starting the function of the choke is to produce a high voltage impulse given by the relation $\mathrm{e}=\mathrm{Ldi} / \mathrm{dt}$ which is necessary for ionization the gas inside the tube at low pressure. Here the basic property of an inductor which is to oppose the rate of change of current is utilized. This is done by the production of a voltage impulse. But a capacitor opposes change in voltage. Since it is connected in parallel with the inductor, it tends to oppose the high voltage impulse produced by the inductor. This in turn results in a current given by $\mathrm{i}=\mathrm{Cdv} / \mathrm{dt}$. When the switch is put on the current in the inductor tends to change due to the continuous make-break action of the starter. The inductor opposes this change by the 
production of high voltage impulse. The capacitor plays its part in trying to oppose this rising voltage and tries to force a current through the choke. So the entire phenomenon of induced voltage and charging current is confined to the local circuit containing the parallel combination of choke and capacitor. No high voltage pulse is available for ionization. Hence ionization is not possible and the fluorescent lamp fails to start.

Another way is to allow the tube light to start normally (without any capacitor across the choke). As the tube becomes lit, the capacitor can be put in to the circuit. This requires an additional switch. But as soon as the capacitor is connected, the light output of the lamp decreases drastically. This occurs due to increase in voltage drop across the choke. Now if a load is put across the choke the voltage drop across the choke decreases and the light output increases. This load can be increased till the lamp starts operating with its normal lumen output. With the capacitor put across the choke, more loads can be put across the choke than that without a capacitor. This is a great method of extracting energy from the choke.

\section{$>$ Experiment no.6}

After the tube light attained its normal operating state a load was connected across the starter terminals. But the observations made were quite contradictory from the earlier experiments. While in the earlier experiments connecting a load across the choke made the tube brighter, connecting the same across the starter made the tube dimmer. A $100 \mathrm{~W}$ lamp completely extinguished the tube light. Connecting a load across the choke and the starter at the same time revealed an interesting fact. When $100 \mathrm{~W}$ load is put across the choke and a $60 \mathrm{~W}$ load is put across the starter, the tube remains alight. But when a $60 \mathrm{~W}$ lamp is put across the choke and a $100 \mathrm{~W}$ across the starter the tube gets extinguished. When one lamp is connected, the glow of the other decreases. But on connecting a $2.5 \mu \mathrm{F}$ capacitor across the starter, the glow of the lamp connected across the choke increases.

\section{$>$ Experiment no. 7}

The variation of operating power factor with variation in connected load across the choke was plotted in a curve.

\section{Graph no.5}



As is seen from the curve the power factor increases almost linearly with increase in load put across the choke. The extrapolated trend line shows that unity power factor will be reached at a load of around $160 \mathrm{~W}$. But such a huge load can not be normally connected because it would damage the filament of the tube light by increasing the voltage across it. So it is self explicit that unity power factor can not be reached. But magnetic ballast has an 'unaided' working power factor of .5 as supplied by the manufacturers. This can be easily increased to .7 (or close to .8 in some cases) by connecting a suitable load across the choke. 
Experiment no. 8

In this experiment a rheostat was connected in series with the tube light supply in order to vary the supply voltage to the device. A suitable load was connected across the choke. The voltage was varied from zero to full value $(230 \mathrm{~V})$. For resistive loads such as incandescent lamps, the light struck even at lower voltage of $200 \mathrm{~V}$. The striking ability reduced with increase in load. The similar effect was noticed in case of an inductive load. But capacitor did not allow the light to strike. Only a whitish glow at the two ends of the tube was visible.

Observations: Energy can be extracted from the choke of a tube light in two forms viz. D.C and A.C. D.C nowadays is not used for domestic purposes. Loads operated from the choke operate at a lower value of voltage compared to their rated one and hence don't produce maximum output. However a fan may be made to operate at a lower voltage instead of using a regulator. A television set may be operated in the same way because it works over a large range of voltage. Almost 20\% energy is saved is such cases. But on using a rotating load such a fan the tube light shows a tendency to flicker. Putting in another way, the stroboscopic effect is much more pronounced. However it is not advisable to put loads $>100 \mathrm{~W}$ across the choke. Battery chargers work very efficiently when connected across the choke. Under any circumstance the following occur:-

a. Lumen output of the tube light would increase.

b. Power factor would be improved.

The loads esp. if they are inductive must be connected only after the tube light has struck. Otherwise it may not strike at all (explained earlier).

\section{Results and Discussions:}

The important results may be summarized as follows:

A. A load may be connected across an inductive choke of a fluorescent lamp to extract a part of the energy wasted in the choke.

B. The load should be preferably resistive, such as incandescent lamps.

C. The connected load has a limited value beyond which it can not be increased to avoid filament damage of the tube light.

D. The power factor improves to an extent but does not reach unity.

E. In general the load across the choke must be connected after the fluorescent lamp assumes its normal operation.
F. A capacitor connected across the choke does not allow the lamp to strike.

G. A capacitor may be connected to the choke only after the tube assumes its normal operation. In this case the load that may be put across a choke has a higher value than the one which may be connected without using a capacitor.

H. Whenever a load is connected across the choke, the lumen output of the lamp increases. However this is not the case if only a capacitor is connected across the choke. In this case the lumen output drastically decreases.

I. Since the voltage across the choke load combination is less than $230 \mathrm{~V}$ (the voltage rating of most single phase loads), the load does not operate at its rated capacity.

J. The load may be connected across the starter terminals after the tube light has lit up. But it has a tendency of extinguishing the tube light.

$\mathrm{K}$. The load that may be put across a starter is much less than that which may be put across a choke. So extraction of energy from the starter terminals is only possible for loads $\leq 15 \mathrm{~W}$. This is not an efficient method of energy extraction. As the permissible load is small, the power factor does not show much improvement.

So instead of replacing an old tube light with a new one, we can easily connect a suitable load across the choke. This would increase the light output as well as the power factor. In this way discarding of magnetic ballast may also be avoided.

\section{Conclusion:}

Fluorescent lamps which are common sources of providing light in homes conventionally operate using a choke and a starter. The low power factor and the energy wastage problems may be taken care of by connecting a suitable load across the choke. Loads such as televisions operate over a wide range of voltage generally show normal operation unless the voltage drops below $100 \mathrm{~V}$. So a T.V may also be connected across the choke. This is particularly useful for old tube lights whose light tube light output has deteriorated with aging. Instead of discarding the old tube light, a load may be connected across the choke to improve its performance. The method is quite simple, inexpensive and easy to implement.

\section{Acknowledgements:}

This research has been financed and constantly encouraged by Mr. P.B Nandi and Mrs. K. Nandi. 